\title{
Water and socioeconomic dependencies: A multiregional model
}

Miguel A. Almazán-Gómez ${ }^{\mathrm{a}, \mathrm{c}^{*}}$, Rosa Duarte ${ }^{\mathrm{a}, \mathrm{c}}$, Raquel Langarita ${ }^{\mathrm{b}, \mathrm{c}}$, Julio Sánchez-Chóliz ${ }^{\mathrm{a}, \mathrm{c}}$

${ }^{a}$ Department of Economic Analysis - University of Zaragoza, Zaragoza, Spain

${ }^{\mathrm{b}}$ Department of Economics and Business Studies - University of La Rioja, Logroño, Spain

c IA2-AgriFood Institute of Aragon, Calle Miguel Servet, 177, 50013, Zaragoza, Spain

\begin{abstract}
River basins often extend over several regions connected by both water flows and socioeconomic factors. Therefore, water policy and diverse hydrological scenarios can affect socioeconomic variables in other parts of a river basin. This paper proposes a tool combining hydro-economic and input-output models to analyze the socioeconomic impacts of different hydrologic scenarios from a multiregional standpoint. To this end, we have built a monthlybasis hydro-economic model to fit a multiregional input-output table to estimate direct and indirect impacts on value added and employment, bringing together data on water flow and regional demand, sector-based economic analysis and macroeconomic impacts. In a given hydrological scenario, the hydro-economic model determines the output of irrigated farmland in each region and the value added generated by each crop. These data are then processed using the multiregional input-output model to determine socio-economic impacts in each of the regions forming the river basin. This methodology allows evaluation of different water policies, providing a tool for policymakers to estimate socio-economic impacts. Finally, we apply this methodology in two scenarios reflecting the opportunity costs of diverse hydrological scenarios in terms of value added and employment terms to demonstrate its excellent analytic capacity.
\end{abstract}

Keywords: hydro-economic model, multiregional input-output, environmental flows, crop production, water management

*Corresponding author: malmazan@unizar.es 


\section{Introduction}

The availability of fresh water is affected by multiple factors. Climate change implies changes in rainfall and temperatures with diverse consequences worldwide (Hoegh-Guldberg et al. 2018). Moreover, globalization, population growth and changing living standards have adversely affected water quality and availability (Maroušek et al. 2019). These global factors have diverse impacts in different regions, although it is clear that arid and semi-arid areas are the most vulnerable. While climate change might even help agriculture in some regions/areas, hotter weather and drought, accompanied by rising demand for water, are likely to hit farmers hard in arid and semi-arid regions (Moriondo et al. 2010). Meanwhile, Hoegh-Guldberg et al. (2018) warn that rising global temperatures could impair the world's food and biofuel production (Maroušek 2014; Mardoyan and Braun 2015; Hašková 2017). In this light, water management will clearly play a key role in any rational climate change adaptation strategy (Tan and Foo 2018).

Water demand has grown continuously in most parts of the world in recent times, and increasing pressure on water resources could easily become unsustainable or trigger some very unwelcome outcomes. The sustainability of water systems must be ensured, then, to conserve the social an economic benefits of access to quality water resources (Hai et al. 2015). According to Arthington et al. (2018), this will require setting strict targets for Environmental Flows (EF) into river basins. The EF define the quantity, timing and quality of the water flows needed to ensure sustainability under variable conditions (Acreman and Ferguson 2010).

Environmental Flows provide environmental and economic benefits for users and nonusers alike (Perni et al. 2012). However, EF also condition agricultural and industrial uses, particularly in arid and semi-arid regions, and they represent a constraint on other consumptive uses (Bonsch et al. 2015). , The methodology we propose in this paper combines a hydro-economic model with a multiregional input-output framework to show the relationships between selected global and regional variables and to identify and analyze the potential socioeconomic impacts of higher EF.

Hydro-economic modeling is a powerful tool for the analysis of water scarcity, drought, and climate change issues. Moreover, hydro-economic models successfully capture at least some of the effects arising from interactions between the hydrological and the economic systems in any region or river basin, helping to ensure that optimal economic outcomes take 
the spatial distribution of water resources into account. Meanwhile, the spatial location of water users with respect to a river's flow captures the magnitude of the chain of impacts arising from local allocation decisions and policy initiatives to cope with water scarcity (Harou et al. 2009; Maneta et al. 2009).

A number of published hydro-economic models are designed to evaluate water allocation policies (George et al. 2011), while others analyze inter-sector water allocation, water markets and pricing, and climate change. For example, Pulido-Velázquez et al. (2008) developed a monthly-basis hydro-economic model to assess trade-offs with environmental requirements, and López-Díaz et al. (2018) construct a water-energy-food nexus model to throw light on the conflict between economic and environmental concerns arising from biofuel production in Mexico. Meanwhile, Akter et al. (2014) propose a hydro-ecological-economic model to evaluate water policies taking the Murray-Darling River Basin in Australia as the case study for their analysis. Finally, Kahil et al. (2015) and (2016) discuss measures to mitigate climate change in arid and semi-arid regions using an annual-basis model, and Crespo et al. (2019) propose a hydro-economic model to evaluate the trade-off between EF and consumptive water uses. Further explanations and a detailed review of the literature on hydro-economic models can be found in Harou et al. (2009).

Given the extent of many river basins, multiregional input-output models are ideal for our purposes, because they describe the relationships between the different regional economies, industries, consumers, and other agents within a multiregional economy. They also show trade flows between different sectors and regions with a high level of disaggregation, revealing dependencies between productive sectors and final demand (including its components, e.g. government and households). Moreover, such input-output tables can be extended by including environmental data (satellite accounts) to analyze water needs and embodied water flows both globally and at the level of individual regions.

An input-output framework is used to analyze inter-agent water relationships and water footprints. Hoa et al. (2018) examine the relationship between economic activities and water pollution in Vietnam using an environmentally-extended input-output model.Meanwhile, Cazcarro et al. (2019) use multirregional input-output (MRIO) and computable general equilibrium models (CGEMs) to assess regional reallocation criteria designed to reduce water constraints in the Spanish economy, and White et al. (2015) study water footprints and water stress in China's Hai River Basin using a multisectoral model. Antonelli et al. (2012) analyze green and blue virtual water flows in the Mediterranean region using an input-output 
framework, and Cazcarro et al. (2016) look at grey water footprints in Spain. Finally, Cai et al. (2017) describe a multiregional model used to analyze virtual grey water flows across 30 Chinese regions.

This paper describes a methodology linking a monthly-basis hydro-economic model, which captures the main uses of the Ebro's waters (irrigation, urban consumption, industrial uses and regional environmental requirements) in the principal regions of the river basin, with a MRIO model specifically designed to capture the socio-economic effects of certain water policies and exogenous changes in water availability. As a case study, we focus on the Ebro River Basin, which is extends across various regions in north-eastern Spain. The combination of hydro-economic and MRIO modeling enabling simultaneous analysis of water use and socioeconomic dependencies in a geographic territory is the main contribution made by this paper to the literature.

To the best of our knowledge, this approach is novel insofar as no such combination of hydro-economic and input-output models has been used before to estimate the socioeconomic impacts of changes in water allocation criteria and use. To begin with, the hydro-economic model is used to establish farm output for the irrigated crops grown in each region under a given set of conditions constituting a direct impact. The resulting data are then included in the multiregional input-output model to determine the new economic equilibrium arising and the total impact on socioeconomic variables. Then, all sectors and regions will experience impacts on income (value added, (VA)) and employment, and on other macroeconomic variables (demand, trade flows and so on). This combination of models allows examination of a wide range of alternatives under different scenarios, linking specific hydrological changes with their macroeconomic impacts on the economy.

We analyze two different water constraint scenarios here, combining hydro-economic and input-output models based on the approach outlined above. In the first scenario, EF are set at $50 \%$ of upstream inflows in all river reaches. In the second, EF in the Delta are progressively increased in percentage terms beginning at the current legal level. Hence, the first scenario shows the effects of increasing EF throughout the river basin, reflecting the distribution of impacts both upstream and downstream; and the second reflects the overall socioeconomic effects of EF at the river mouth. This approach underscores both the applicability of our integrated hydro-economic and input-output model to the analysis of environmental and economic issues in a multiregional area such as a river basin, and the importance of studying 
the impacts produced by water constraints holistically, given linked nature of the effects observed.

The rest of this paper is organized in three sections - Methodology and Data, Results, and Discussion and Conclusions. The first of these contains a brief contextualization of the Ebro River Basin (ERB) case study followed by a description of the hydro-economic model proposed and, finally, and explanation of the multiregional input-output table and method applied to include the results from the hydro-economic model in the multiregional inputoutput framework. The Results section begins with a description of the scenarios considered followed by results obtained for each, focusing mainly on value added and employment impacts. Finally, the Discussion and Conclusions section explains the relevance of the main findings from the study and highlights the need further research in this area.

\section{Methodology and Data}

\section{Brief contextualization of the ERB}

This study area is situated in the northeast of Spain. As shown in Figure 1, the Ebro River crosses seven of Spain's autonomous communities, as the country's devolved political regions are known. These are Cantabria (where the river's headwaters arise), Castile-Leon, the Basque Country, La Rioja, Navarre, Aragon, and Catalonia (where it eventually runs into the Mediterranean Sea). The ERB covers an area of $85,569 \mathrm{~km}^{2}$, making it the biggest river basin in Spain and one of the most important semi-arid basins in the whole of the Mediterranean region (Milano et al. 2013). The river's mean annual discharge into the sea is $9,281 \mathrm{hm}^{3}$, and the ERB's mean annual runoff is $14,500 \mathrm{hm}^{3}$. There are 125 reservoirs in the ERB counts with a total stock capacity of $7,833 \mathrm{hm}^{3}$, or $54 \%$ of mean annual runoff, along with an extensive network of canals carrying water to favored locations for irrigated farming. The ERB has some $5,744 \mathrm{~km}^{2}$ of irrigated farmland, and agriculture of this kind is its most waterintensive activity, requiring between 4,500 and 5,000 $\mathrm{hm}^{3} /$ year, compared to consumption of around $500 \mathrm{hm}^{3} /$ year by all other users combined.

The map shown in Figure 1 focuses on the hydrological features of the ERB and irrigated land, which accounts for the lion's share of water demand, as well as reflecting the multiregional nature of the river basin. Figure 1 thus illustrates the background to the hydroeconomic model. 


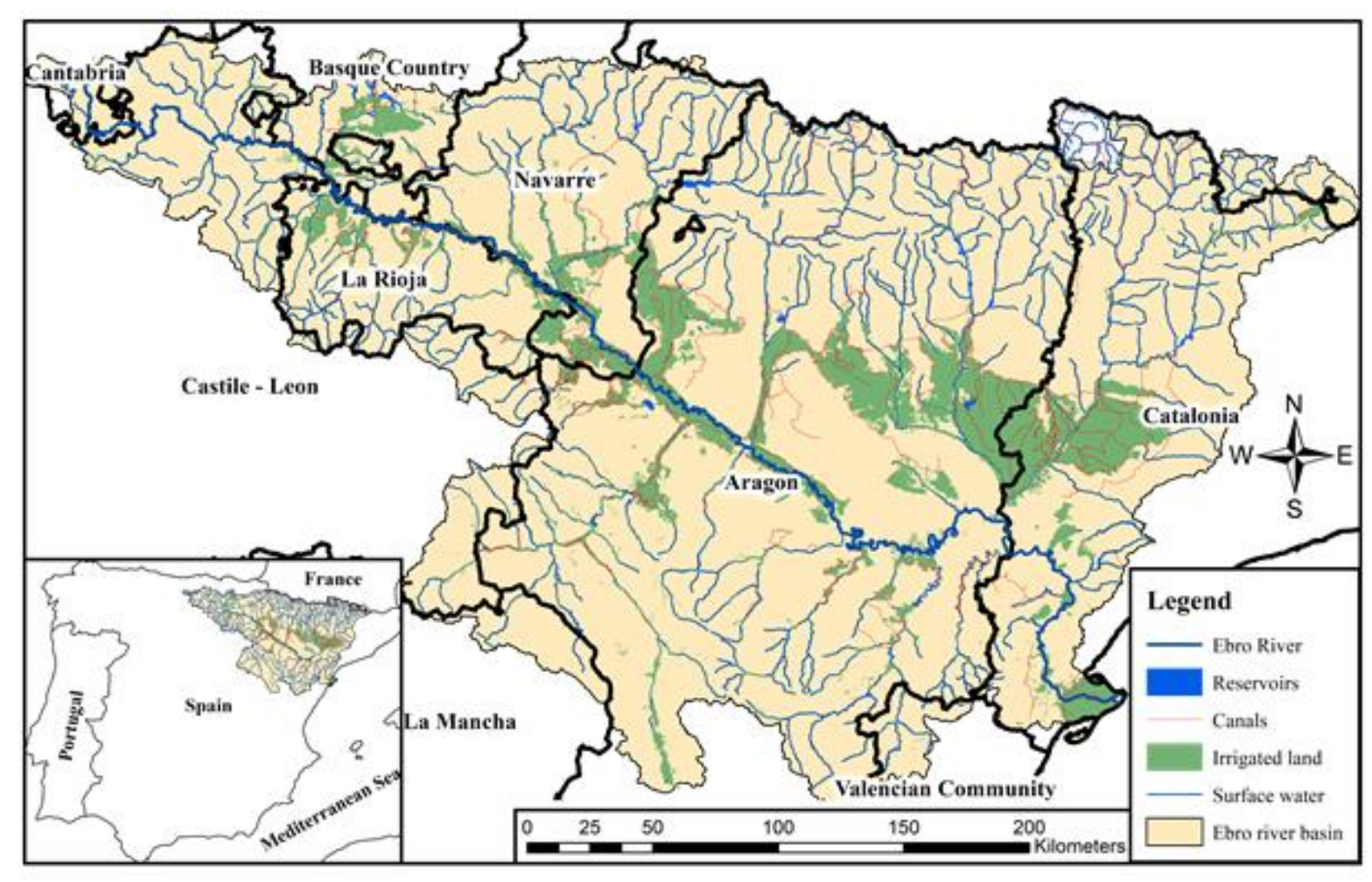

Fig. 1 The Ebro river basin. Northeastern Spain. Source: Own work. The thick black lines depict regional boundaries. The Basque Country, Navarre, La Rioja, Aragon, and Catalonia are the key regions.

Legally binding environmental flows in the ERB are set and regulated by the ERB Authority (Confederación Hidrográfica del Ebro, CHE), which is also responsible of preparing, auditing and implementing annual management plans for the river basin. These processes include public scrutiny by stakeholders (farmers, industry, local councils and environmental organizations), as required by the Water Framework Directive (Ballester and Mott Lacroix 2016).

Table SI1 in the Supplementary Information (SI) shows the legally binding EF established by the ERB Authority and the proposals for EF in the Ebro Delta made by the Catalan Water Agency (ACA, in Catalan acronym) and the Technical Commission on the Sustainability of the Lower Ebro (CSTE in Catalan). These two proposals would entail annual environmental water demand in the Delta in a range of between $195 \%$ and $416 \%$ of the legal EF. Possible alternatives to attain these proposed goals are analyzed in Almazán-Gómez and SánchezChóliz (2016). Crespo et al. (2019) also analyzes the potential impact of the ACA and CSTE proposals on VA in the ERB applying an annual-basis hydro-economic model. Meanwhile, Almazán-Gómez et al. (2018) argue that water shortages in the ERB are not determined by overall annual availability, but by the distribution of the available water over the whole of the year and by the capacity of storage infrastructures. In this regard, we may note that the ERB 
in fact defines EF in monthly terms, and according to Pulido-Velázquez et al. (2008) it is usually enough to record hydrological changes at monthly intervals to capture the seasonal behavior of water demand. In this light, we opted to consider monthly water flows and demand in the hydro-economic model described. The model developed here is based on monthly water data recorded over the course of one water year (October 1 - September 30).

\section{The hydro-economic model}

The hydro-economic model treats the autonomous communities crossed by the ERB as water-use nodes. These (political) regions each have their own water sources (tributaries, runoff, etc.) and points of water use, simplified as shown in Figure 2. This model is made up of 9 head flows, 5 water-use schemes, 5 reservoirs, and a number of virtual gauging stations. The arrows indicate the relationships between these components.

The hydro-economic model includes not only the above mentioned hydrological and socioeconomic components, but also physical and environmental constraints and an optimization equation. The hydrological components of the model comprise basically water availability and water flows (rivers and reservoirs), as shown in Figure 2. Water availability is determined by the head flows and the initial water stored in reservoirs. Monthly water inflows, represented by the head flows (HF_x), are then routed between the nodes or stored, in line with basic hydrological theory. In this node-link network, nodes represent physical units impacting the stream system and links represent the connections between them. In the model, Water either passes from one node to the next one (or it is stored) in the model, representing in outline the actual water flows recorded in the river basin. The nodes refer to geographical areas of different sizes (e.g. river stretches, reservoirs and user regions). Meanwhile, the socioeconomic components of the model replicate the behavior of farmers and hence the demand for irrigation water for the irrigated crops grown in each region (water-use area), as well as other industrial uses and requirements, and drinking and sanitation water, which are represented by constants (because they are not decisional variables). The physical constraints established ensure that there are no negative flows and set maximum limits on water stored in reservoirs, while environmental constraints consist of minimum flows at specific nodes and minimum stocks held in reservoirs. These constraints take the form of upper and lower monthly boundary conditions in the model, which is sufficiently versatile to allow for the option of including additional institutional constraints to establish allocation rules or different scenarios. Finally, the optimization equation in this work seeks to maximize the VA generated by crop production given the components and constraints included in the model. 


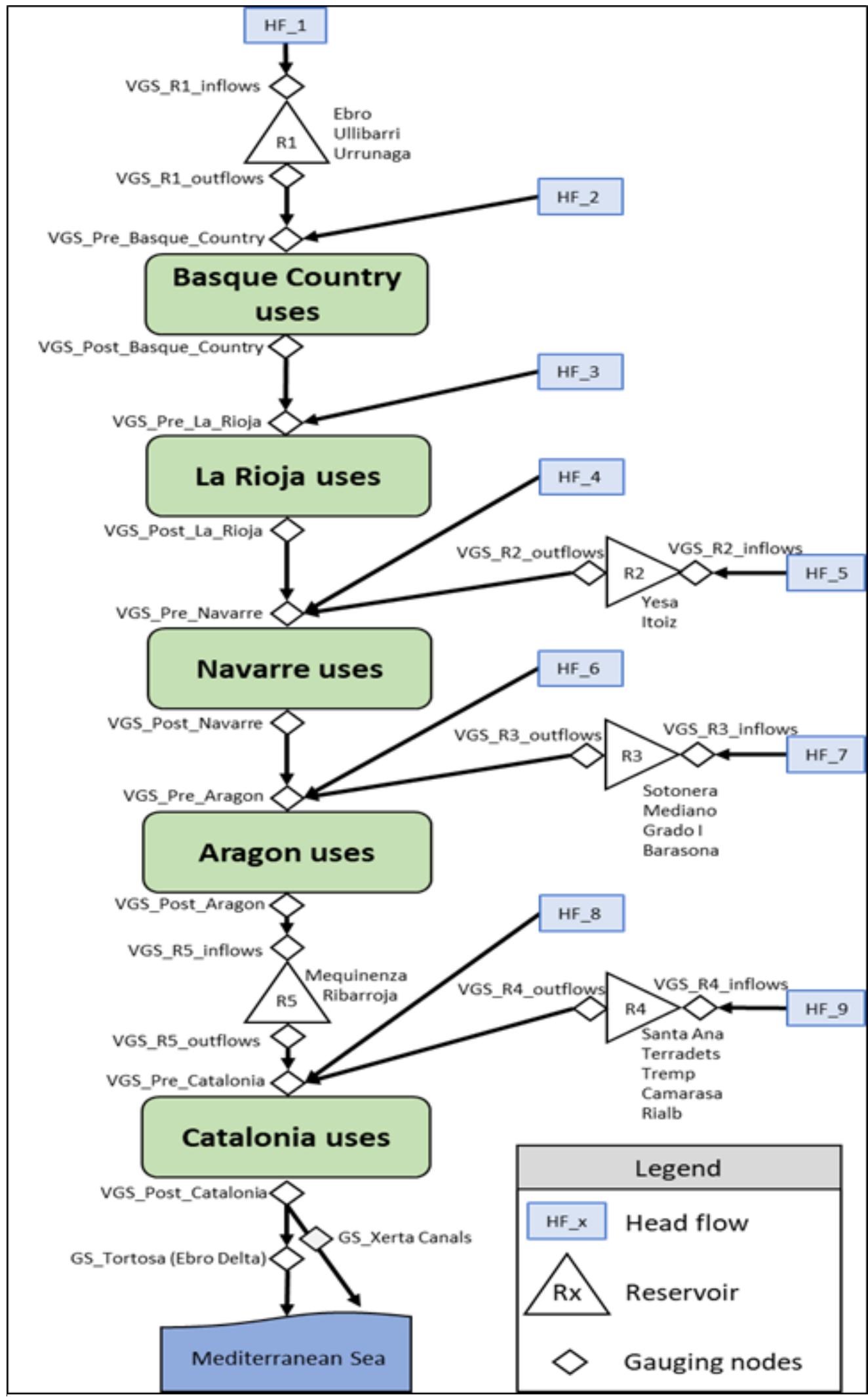

Fig. 2 Schematic outline of the Ebro River Basin surface water network. Source: Own work. Green areas depict water-demand nodes (water-use areas), which match the regions considered in the MRIO table. Arrows indicate the relationships between nodes. Stock nodes (reservoirs) are depicted by triangles. 
The simplified hydrological model of the river basin is based on the principles of water mass balance and continuity of flow, which determine the volume of water availability in the different reaches of the river and water stocks in reservoirs (equations (1)-(3)). The available water can be used for economic activities within the bounds of the environmental restrictions modeled by equation (4). Specifically, equation (1) represents surface water flow continuity, meaning that the water that entering a given node each month $\mathrm{w}_{\mathrm{in}_{\mathrm{d}, \mathrm{m}}}$ is the sum of all water arriving from upstream. These inflows may come from a head flow or from other nodes. Equation (2) determines the available water after all uses have been taken into account, and the result obtained must be positive. In the flow (but not stock) nodes where no water is consumed (i.e. gauging or diversion nodes) the water outflow is equal to the water inflow. Meanwhile, the water consumed at water-use schemes is subtracted, so that the outflow is the difference between consumptive use and the water inflow. Equation (3) is the mass balance equation for stock nodes (reservoirs), which states that the water stock in reservoirs for each month is the stock of the previous month increased by inflows and reduced by outflows. Finally, Equation (4) represents the EF constraint. This equation applies only for some nodes (see the Supplementary Information for further details). Together these four equations determine the available water in the different areas that can be used considering monthly physical and environmental constraints.

$$
\begin{gathered}
\mathrm{w}_{\mathrm{in}_{\mathrm{d}, \mathrm{m}}}=\sum_{\mathrm{j}} \beta_{\mathrm{j}, \mathrm{d}} \mathrm{w}_{\mathrm{out}_{\mathrm{j}, \mathrm{m}}}+\mathrm{HF}_{\mathrm{d}, \mathrm{m}} \\
0<\mathrm{w}_{\text {out }_{\mathrm{d}, \mathrm{m}}}=\mathrm{w}_{\mathrm{in}_{\mathrm{d}, \mathrm{m}}}-\mathrm{USE}_{\mathrm{d}, \mathrm{m}}^{\mathrm{URB}}-\mathrm{USE}_{\mathrm{d}, \mathrm{m}}^{\mathrm{IRR}} \\
0<\mathrm{S}_{\mathrm{r}, \mathrm{m}}=\mathrm{S}_{\mathrm{r}, \mathrm{m}-1}+\sum_{\mathrm{j}} \beta_{\mathrm{j}, \mathrm{r}} \mathrm{w}_{\text {out }_{\mathrm{j}, \mathrm{m}}}-\mathrm{w}_{\text {out }_{\mathrm{r}, \mathrm{m}}} \\
\mathrm{w}_{\text {out }_{\mathrm{d}, \mathrm{m}}} \geq \mathrm{E}_{\mathrm{d}, \mathrm{m}}^{\mathrm{min}}
\end{gathered}
$$

$\mathrm{w}_{\mathrm{in}_{\mathrm{d}, \mathrm{m}}}$ is the total water inflow into a river reach " $\mathrm{d}$ " in month " $\mathrm{m}$ ", and $\mathrm{w}_{\mathrm{out}_{\mathrm{j}, \mathrm{m}}}$ is the water outflow from a river reach " $\mathrm{j}$ " in month " $\mathrm{m}$ ". $\beta_{\mathrm{j}, \mathrm{d}}$ is the portion of water from river reach " $\mathrm{j}$ " that ends up in river reach " $d$ ". $H F_{d, m}$ is the runoff entering river reach " $d$ " in month " $\mathrm{m}$ " (head flows). USE $\mathrm{d}_{\mathrm{d}, \mathrm{m}}^{\mathrm{URB}}$ is the water diverted for urban and other uses (all productive activities except for irrigation) in river reach " $\mathrm{d}$ " and month " $\mathrm{m}$ ". Meanwhile, USE $\mathrm{d}_{\mathrm{d}, \mathrm{m}}^{\mathrm{IRR}}$ represents the water diverted for irrigation in river reach " $d$ " and month "m". $S_{r, m}$ is the 
water stored in reservoir " $\mathrm{r}$ " in month " $\mathrm{m}$ ", and $\mathrm{E}_{\mathrm{d}, \mathrm{m}}^{\mathrm{min}}$ is the minimum EF established for river reach "d" and month "m".

As shown in Figure 2, demand nodes are associated with the river basin's regions, which are also represented in the multiregional input-output model of the river basin. Drinking water and urban supply are priority uses, while the apparent water productivity obtained from all other productive activity except irrigated farming is very significant (Almazán-Gómez et al. 2019), and in this light we treat these sources of water demand as fixed parameters in equation (5). Equation (6) represents agricultural water needs (irrigation).

$$
\begin{gathered}
\operatorname{USE}_{\mathrm{d}, \mathrm{m}}^{\mathrm{URB}}=\sum_{\mathrm{f}} \frac{\mathrm{Wr}_{\mathrm{d}}^{\mathrm{f}} * \mathrm{Q}_{\mathrm{d}}^{\mathrm{f}}}{12}+\frac{1}{12} \mathrm{Wr}_{\mathrm{d}}^{\mathrm{pc}} * \mathrm{Pop}_{\mathrm{d}} \\
\mathrm{USE}_{\mathrm{d}, \mathrm{m}}^{\mathrm{IRR}}=\sum_{\mathrm{c}} \mathrm{USE}_{\mathrm{d}, \mathrm{m}}^{\mathrm{IRR}, \mathrm{c}}=\sum_{\mathrm{c}} \mathrm{Wr}_{\mathrm{d}, \mathrm{m}}^{\mathrm{c}} * \mathrm{~h}_{\mathrm{d}}^{\mathrm{c}} ; \mathrm{USE}_{\mathrm{d}, \mathrm{m}}^{\mathrm{IRR}, \mathrm{c}}=\mathrm{Wr}_{\mathrm{d}, \mathrm{m}}^{\mathrm{c}} * \mathrm{~h}_{\mathrm{d}}^{\mathrm{c}}
\end{gathered}
$$

$\mathrm{USE}_{\mathrm{d}, \mathrm{m}}^{\mathrm{URB}}$ represents water diversion for urban proposes (drinking water and sanitation, as well as other productive activities) in the region associated with river reach " $\mathrm{d}$ " in month " $m$ ". $W r_{d}^{f}$ is the water required to obtain one monetary unit of output in sector " $\mathrm{f}$ " and river reach " $d$ ". $Q_{d}^{f}$ is the annual output (in euros) of sector " $\mathrm{f}$ " in river reach " $d$ ". We assume uniform monthly distribution of annual output. $\mathrm{Wr}_{\mathrm{d}}^{\mathrm{pc}}$ is the per capita annual water requirement (drinking water plus urban uses) in river reach " $\mathrm{d}$ " and $\mathrm{Pop}_{\mathrm{d}}$ is the associated population. Note that river reaches are regions insofar as they relate to demand notes.

Likewise, $U S E_{d, m}^{I R R}$ represents water diversion for irrigated farming in the region associated with river reach " $\mathrm{d}$ " in month " $\mathrm{m}$ ". In the case of irrigation, water requirements depend directly on land use for each crop "c $c$ ". USE $E_{d, m}^{I R R, c}$ is the water that must be diverted to grow crop "c" in river reach " $\mathrm{d}$ " and month " $\mathrm{m}$ ". $\mathrm{Wr}_{\mathrm{d}, \mathrm{m}}^{\mathrm{c}}$ is the net water requirement per hectare to grow crop "c" in river reach " $\mathrm{d}$ " and month " $\mathrm{m}$ ", and $\mathrm{h}_{\mathrm{d}}^{\mathrm{c}}$ is the area in hectares under crop "c" in river reach "d". Net water requirements are used here because the model assumes that water returns to the same region. The specific data for land use and monthly water requirements are provided in the Supplementary Information.

A Ricardian function of average land productivity is assumed for irrigated agriculture. Therefore, the average productivity of the land for each crop is determined by a decreasing function, so that output per hectare will decrease in a given region when land use increases, while costs per hectare will remain constant. For the sake of simplicity these functions are 
linear, see equation (7), where $\psi_{\mathrm{c}}^{\mathrm{d}}$ is the average productivity per hectare, $\beta_{0}^{\mathrm{c}, \mathrm{d}}$ is the intercept term, and $\beta_{1}^{\mathrm{c}, \mathrm{d}}$ (always negative) is the slope. The value of these parameters is shown in the Supplementary Information. Meanwhile, we assume that the inputs required per hectare of irrigation scheme " $d$ " for each crop " $c$ " in each sector "i" and region " $r$ " $\left(\phi_{i, c}^{r, d}\right)$, and therefore production costs, are constant and can be obtained from the input-output table. Hence, costs per hectare $\left(\phi_{\mathrm{c}}^{\mathrm{d}}\right)$ are also constant $\left(\phi_{\mathrm{c}}^{\mathrm{d}}=\frac{\sum_{\mathrm{r}} \sum_{\mathrm{i}} \mathrm{z}_{\mathrm{i}, \mathrm{c}}^{\mathrm{r}}}{\mathrm{h}_{\mathrm{c}}^{\mathrm{d}}}\right)$. The profit generated by each crop in each region $\left(\pi_{c}^{d}\right)$ can be expressed as shown in equation (8). The target function of the model is to maximize the total irrigation profits for the whole river basin (equation (9)), taking into consideration equations (1-8) and the constraints established. The main data used in the model is provided in the Supplementary Information.

$$
\begin{gathered}
\psi_{\mathrm{c}}^{\mathrm{d}}=\beta_{0}^{\mathrm{c}, \mathrm{d}}+\beta_{1}^{\mathrm{c}, \mathrm{d}} \mathrm{h}_{\mathrm{c}}^{\mathrm{d}} \\
\pi_{\mathrm{c}}^{\mathrm{d}}=\left(\psi_{\mathrm{c}}^{\mathrm{d}}-\phi_{\mathrm{c}}^{\mathrm{d}}\right) \mathrm{h}_{\mathrm{c}}^{\mathrm{d}} \\
\operatorname{Max}: \sum_{\mathrm{d}} \sum_{\mathrm{c}} \pi_{\mathrm{c}}^{\mathrm{d}}
\end{gathered}
$$

\section{MRIO table and frameworks combination}

Multi-region input-output (MRIO) tables are used to reflect trade relationships between regions, producers, and consumers within an economy, showing the interdependencies existing between different industries, economic agents, and territories. As mentioned above, this paper uses an MRIO table with eight regions. Five of them (Aragon, Catalonia, Navarre, Basque Country, and La Rioja) form part of the ERB, while the other three comprise the Rest of Spain, Rest of the EU, and Rest of the world. In this MRIO table, the primary sector appears disaggregated into 18 irrigated crops 18 rain fed crops, 6 livestock groups and the rest of primary sector (mainly forestry and fishing). The structure of the MRIOT is shown in Figure 3 and the sectors included are shown in the Supplementary Information.

\begin{tabular}{|c|c|c|c|c|c|}
\hline $\mathrm{z}_{\mathrm{i}, \mathrm{j}}^{1,1}$ & $\ldots$ & $\mathrm{z}_{\mathrm{i}, \mathrm{j}}^{1,8}$ & $\mathrm{y}_{\mathrm{i}}^{1,1}$ & $\ldots$ & $\mathrm{y}_{\mathrm{i}}^{1,8}$ \\
\hline$\vdots$ & $\mathrm{z}_{\mathrm{i}, \mathrm{j}}^{\mathrm{r}, \mathrm{s}}$ & $\vdots$ & $\vdots$ & $\mathrm{y}_{\mathrm{i}}^{\mathrm{r}, \mathrm{s}}$ & $\vdots$ \\
\hline $\mathrm{z}_{\mathrm{i}, \mathrm{j}}^{8,1}$ & $\cdots$ & $\mathrm{z}_{\mathrm{i}, \mathrm{j}}^{8,8}$ & $\mathrm{y}_{\mathrm{i}}^{8,1}$ & $\ldots$ & $\mathrm{y}_{\mathrm{i}}^{8,8}$ \\
\hline
\end{tabular}




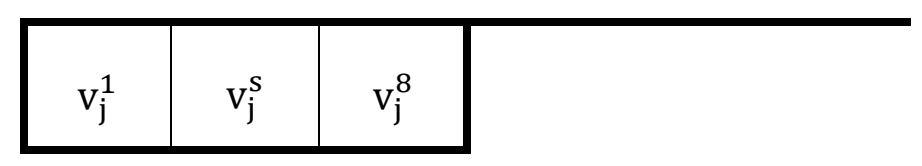

Fig. 3 Structure of the MRIO table. Each $\mathrm{z}_{\mathrm{i}, \mathrm{j}}^{\mathrm{r}, \mathrm{s}}$ represents sales made by sector "i" in region " $\mathrm{r}$ " to sector " $\mathrm{j}$ " in region " $s$ ". $y_{i}^{r, s}$ represents the components of the final demand matrix Y. Each $y_{i}^{r, s}$ represents sales from sector "i" in region " $r$ " to meet final demand in region " $s$ ". $v_{j}^{s}$ represents the VA of sector " $\mathrm{j}$ " in region "s".

The table's columns show the production structure of each sector in each region and its dependencies on other sectors and other regions. Meanwhile, the rows reflect the destination of output. Since the table represents a closed economy (the whole world), the sums of the columns are equal to the sums of the rows (see equation (10)).

$$
\sum_{\mathrm{r}} \sum_{\mathrm{i}} \mathrm{z}_{\mathrm{i}, \mathrm{j}}^{\mathrm{r}, \mathrm{s}}+\mathrm{v}_{\mathrm{j}}^{\mathrm{s}}=\sum_{\mathrm{z}} \sum_{\mathrm{u}} \mathrm{z}_{\mathrm{j}, \mathrm{u}}^{\mathrm{s}, \mathrm{z}}+\sum_{\mathrm{z}} \mathrm{y}_{\mathrm{j}}^{\mathrm{s}, \mathrm{z}}=\mathrm{x}_{\mathrm{j}}^{\mathrm{s}} ; \forall \mathrm{i}, \mathrm{j}, \mathrm{r}, \mathrm{s}, \mathrm{u}, \mathrm{z}
$$

MRIO models can be used to analyze environmental and socioeconomic impacts, distinguishing between different sectors and regions. These models allow identification of direct and indirect impacts and analysis of the interactions between environmental and socioeconomic systems (White et al. 2015). First, the matrix of technical coefficients, A, is obtained from the MRIO table, representing direct inputs needed from sector "i" in region " $r$ " per euro of output produced by sector " $j$ " in region " $s$ ". The matrix components are the $a_{i, j}^{r, s}$ values calculated using equation (11), while the matrix formula is described in equation (12).

$$
\begin{aligned}
a_{i, j}^{r, s} & =\frac{z_{i, j}^{r, s}}{x_{j}^{s}} ; x_{j}^{s}=\sum_{r} \sum_{i} z_{i, j}^{r, s}+v_{j}^{s} \\
x & =A x+Y u \leftrightarrow x=(I-A)^{-1} Y u
\end{aligned}
$$

where $\mathrm{x}_{\mathrm{j}}^{\mathrm{s}}$ represents the total output of sector " $\mathrm{j}$ " in region " $\mathrm{s}$ "; $\mathrm{I}$ is the identity matrix, $\mathrm{Y}$ is the final demand matrix, $u$ is an $8 \times 1$ column vector of ones, $(I-A)^{-1}$ is the Leontief inverse, which indicates the inputs directly and indirectly needed from sector "i" in region "s" per euro of final demand of sector " $\mathrm{j}$ " of region " $\mathrm{r}$ "; $\mathrm{x}$ is the $428 \mathrm{x} 1$ Gross Output vector; and $\mathrm{y}=\mathrm{Yu}$ is the final demand aggregated vector $\left(y_{i}^{r}=\sum_{s} Y_{i}^{r, s}\right)$.

In a hydrological scenario, the hydro-economic model determines the optimal mix of irrigated crops and the production of each crop in each region. Once the irrigated crop production is known, we can calculate the direct impact on VA and jobs using equations (13) and (14) respectively. Equation (13) determines the percentage changes in value added 
associated with changes in net profits, while equation (14) identifies the percentage changes in jobs resulting from changes in land use.

$$
\begin{gathered}
\mathrm{va}_{\mathrm{c}, 1}^{\mathrm{d}}=\mathrm{va}_{\mathrm{c}, 0}^{\mathrm{d}}\left(\pi_{\mathrm{c}, 1}^{\mathrm{d}} / \pi_{\mathrm{c}, 0}^{\mathrm{d}}\right) \\
\mathrm{emp}_{\mathrm{c}, 1}^{\mathrm{d}}=\mathrm{emp}_{\mathrm{c}, 0}^{\mathrm{d}}\left(\mathrm{h}_{\mathrm{c}, 1}^{\mathrm{d}} / \mathrm{h}_{\mathrm{c}, 0}^{\mathrm{d}}\right)
\end{gathered}
$$

Sub-index 0 in equations (13) and (14) refers to the initial (pre-shock) values observed and sub-index 1 shows the results obtained from the hydro-economic model following a change in the hydrological scenario (post-shock values). $\mathrm{va}_{\mathrm{c}}^{\mathrm{d}}$ is the VA associated with crop "c" in region "d", and emp $\mathrm{c}_{\mathrm{c}}^{\mathrm{d}}$ represents the total jobs needed to grow crop "c" in region "d". Hence, the direct impact of each crop on VA in each region is $\left(\mathrm{va}_{\mathrm{c}, 1}^{\mathrm{d}}-\mathrm{va}_{\mathrm{c}, 0}^{\mathrm{d}}\right)$, while the direct impact on employment is $\left(e m p_{c, 1}^{\mathrm{d}}-\mathrm{emp}_{\mathrm{c}, 0}^{\mathrm{d}}\right)$.

The model assumes constant requirements per hectare $\left(\phi_{i, c}^{\mathrm{r}, \mathrm{d}}\right)$, so demand for intermediate crop inputs in each region falls in proportion to any reduction in the area cultivated, as shown in equation (15). Meanwhile, such falls in demand for goods and services in turn lower the sales made by other sectors to farmers producing irrigated crops. This is expressed in equation (16). Hence, the indirect effect on VA and employment is obtained from equations (17) and (18), following Dietzenbacher (2005). Note that every crop production activity is identified as a sector in the MRIO table, and every water-using node is also a region identified in the MRIO table.

$$
\begin{gathered}
z_{\mathrm{i}, \mathrm{c}, 1}^{\mathrm{r}, 1}=\mathrm{z}_{\mathrm{i}, \mathrm{c}, 0}^{\mathrm{r}, \mathrm{s}}\left(\mathrm{h}_{\mathrm{c}, 1}^{\mathrm{s}} / \mathrm{h}_{\mathrm{c}, 0}^{\mathrm{s}}\right) \\
\Delta \mathrm{z}_{\mathrm{i}}^{\mathrm{r}}=\sum_{\mathrm{s}} \sum_{\mathrm{j}}\left(\mathrm{z}_{\mathrm{i}, \mathrm{c}, 0}^{\mathrm{r}, \mathrm{s}}-\mathrm{z}_{\mathrm{i}, \mathrm{c}, 1}^{\mathrm{r}, \mathrm{s}}\right) \\
\Delta \mathrm{va}_{\text {ind }}=\hat{\mathrm{v}}(\mathrm{I}-\mathrm{A})^{-1}(\Delta \mathrm{z}) \\
\Delta \mathrm{emp}_{\text {ind }}=\hat{\mathrm{e}}(\mathrm{I}-\mathrm{A})^{-1}(\Delta \mathrm{z})
\end{gathered}
$$

where $\Delta \mathrm{z}_{\mathrm{i}}^{\mathrm{r}}$ is the change in the consumption of goods and services produced by sector "i" in region " $r$ " caused by changes in irrigated farm output; $\hat{v}$ is the diagonalized vector of VA per euro of total output; $\hat{e}$ is the diagonalized vector of employment per euro; $\mathrm{va}_{\text {ind }}$ are indirect effects on valued added; and $\mathrm{emp}_{\text {ind }}$ are indirect job losses. 


\section{Results}

Two scenarios are presented here to illustrate the model's capacity. The first scenario evaluates the effects of establishing environmental flows equal to $50 \%$ of the monthly natural flow (sum of upstream head flows) in a median water-year in all river reaches (a water-year composed by median monthly water inflows). The environmental requirement established in this scenario extends to all regions of the basin and applies to all water flows. The second scenario analyzes the effects of increasing EF at the river mouth. This scenario simulates the effects of gradually increasing the legally fixed EF in the Delta in steps of 1\%. More than 200 observations were made to establish the adverse incremental impacts on socioeconomic variables caused by increases in EF Delta.

Despite their differing nature, these two scenarios aim to simulate the effects of water constraints on value added and employment throughout the river basin. In both, the head flows taken into account reflect median monthly inflows over the course of a water-year. The head flows detailed by months are provided in the SI. Given the nature of the median wateryear, the situation reflected is close to reasonable flow expectations for each month.

Scenario 1 analyzes the effects on employment and VA of increasing EF to establish an equal distribution between consumptive and environmental uses throughout the river basin by requiring $\mathrm{EF}$ equal to $50 \%$ of natural flows every month across the board. In fact, in the selected case study, the total annual median flow is $12,838 \mathrm{hm}^{3}$, resulting in an EF requirement of $6,419 \mathrm{hm}^{3}$ at the river mouth, leaving another $6,419 \mathrm{hm}^{3}$ available for consumptive uses, a value that is actually higher than the current level of consumptive water use in the basin. As shown in Table 1, however, consumptive use would in fact fall by 207 $\mathrm{hm}^{3}$ in this scenario. The results reflected in Table 1 also reveal that this increase in EF would restrict the water available for consumptive use in irrigation, which would entail the loss of more than 1,100 jobs and almost 50 million Euros of VA in the wider economy. As explained in the methodology section, these results were obtained in two phases from the hydrological part of the model first (effects on irrigated farming in the basin), while the multi-sectoral and multiregional equilibrium was obtained from the MRIO model following the procedure described above. 
Table 1. Changes in VA and Employment in scenario 1 at the regional level

\begin{tabular}{|c|c|c|c|c|c|c|c|c|c|c|}
\hline & \multicolumn{4}{|c|}{ All Sectors } & \multicolumn{4}{|c|}{ Irrigation sector } & \multirow[b]{2}{*}{$\begin{array}{c}\text { Water } \\
\mathrm{hm}^{3}\end{array}$} & \multirow[b]{2}{*}{$\begin{array}{c}\text { Water } \\
\%\end{array}$} \\
\hline & $\begin{array}{c}\text { VA } \\
(, 000 €)\end{array}$ & $\begin{array}{l}\text { Emp. } \\
\text { (jobs) }\end{array}$ & $\begin{array}{c}\text { VA } \\
\%\end{array}$ & $\begin{array}{c}\text { Emp. } \\
\%\end{array}$ & $\begin{array}{c}\mathrm{VA} \\
(, 000 €)\end{array}$ & $\begin{array}{l}\text { Emp. } \\
\text { (jobs) }\end{array}$ & $\begin{array}{l}\mathrm{VA} \\
\%\end{array}$ & $\begin{array}{c}\text { Emp. } \\
\%\end{array}$ & & \\
\hline Aragon & $-37,796$ & -930 & $-0.118 \%$ & $-0.161 \%$ & $-29,675$ & -732 & $-4.829 \%$ & $-4.668 \%$ & -184.66 & $-7.34 \%$ \\
\hline Catalonia & -113 & -3 & $-0.001 \%$ & $-0.001 \%$ & 0 & 0 & $0.000 \%$ & $0.000 \%$ & 0.01 & $0.00 \%$ \\
\hline Navarre & $-5,971$ & -136 & $-0.037 \%$ & $-0.051 \%$ & $-4,825$ & -111 & $-1.868 \%$ & $-1.817 \%$ & -17.77 & $-4.15 \%$ \\
\hline Basque $\mathrm{C}$. & -612 & -20 & $-0.007 \%$ & $-0.011 \%$ & -559 & -18 & $-2.004 \%$ & $-1.8774 \%$ & -1.20 & $-3.02 \%$ \\
\hline La Rioja & $-2,822$ & -79 & $-0.038 \%$ & $-0.057 \%$ & $-2,444$ & -69 & $-1.148 \%$ & $-1.699 \%$ & -4.00 & $-1.87 \%$ \\
\hline Total ERB & $-47,314$ & $-1,168$ & $-0.059 \%$ & $-0.078 \%$ & $-37,504$ & -931 & $-2.194 \%$ & $-1.674 \%$ & -207.64 & $-4.30 \%$ \\
\hline RSP & -221 & -5 & & & & & & & & \\
\hline REU & -196 & -4 & & & & & & & & \\
\hline ROW & -155 & -12 & & & & & & & & \\
\hline TOTAL & $-47,885$ & $-1,189$ & & & & & & & & \\
\hline
\end{tabular}

Note: Data in thousands of euros, jobs, and percentages. RSP $=$ Rest of Spain, REU $=$ Rest of European Union, ROW $=$ Rest of World

Considering only the ERB itself, the impact is just over $€ 47$ million in terms of value added, accompanied by the loss of more than 1,100 jobs, concentrated above all in Aragon, the region with the largest consumptive use of water and the largest farm sector (as a percentage of total value added). While these regional losses might appear low, their impact could be very relevant in some rural areas where is the main source of income. The impact on irrigated farming may be observed on the right of the table. Once again, Aragon stands out, losing value added worth almost 30 million euros and 732 farm jobs. Furthermore, losses in irrigated farming (direct impacts) are generally greater the knock-on effects on the rest of the economy in relative terms-direct impacts in Aragon represent a fall of $4.8 \%$ in irrigated farming income and an increase of almost $4.7 \%$ in irrigated farming unemployment. Catalonia is not directly affected by this scenario, however, because it does not result in any fall in the hectares irrigated or in other consumptive water uses. Finally, last two columns of the table reflect changes in the volume of water used in each region. Once again, Aragon stands out with a drop of $185 \mathrm{hm}^{3}$ in the amount of water used in irrigation, representing a 7\% reduction in the volume consumed by the region. Meanwhile, the volume of irrigation water used drops by $18 \mathrm{hm}^{3}$ in Navarre and $4 \mathrm{hm}^{3}$ in La Rioja. Finally, there is practically no decrease in water use of any kind either in the Basque Country or in Catalonia, which explains low direct impact on irrigated farming in these regions.

Since the restrictions imposed in this scenario are related to the natural monthly flow, the results obtained from the model suggest that resource pressure, defined as the volume of water used in each region in relation to the total water available, is greater in the regions 
where the direct effects on irrigated farming are larger. This is especially important between May and September, the key months for irrigation in Spain. In this light, we may affirm that those regions with high relative water consumption in the key months would suffer the greatest impact from any measure like that proposed in this scenario.

Based on the same methodology and assumptions, Table 2 shows the total impacts on VA and employment of percentage increases in the Delta's EF (data on direct impacts are provided in the SI). The direct impact of this measure is associated with falls in VA and employment losses in irrigated farming due to the decrease in the availability of water for irrigation. Meanwhile the indirect impact is associated decreases in VA and job losses in the wider economy because of shrinking demand for intermediate inputs needed by farmers. The results presented in Table 2 are aggregated by region. Meanwhile, the graphs provided in Figures 4 and 5 reflect the total impact on VA and jobs by region. Figures SI1 to SI4 (in the SI) show the total direct and indirect impact on VA and jobs.

As shown in Table 2, EF could be doubled (100\% increase) in the Delta in a median wateryear without any adverse socio-economic consequences according to the hydro-economic model. As soon as the increase in Delta rises above 101\%, however, crop production begins to decline, resulting in falling VA and job losses. Comparing Table 2 with Table SI12, which presents direct effects, the impact on irrigated farming represents more than $75 \%$ of the total effect in all regions. This is a consequence of the farm sector's low backward coefficients since its products are by nature primary goods (Almazán-Gómez et al. 2019), which makes agriculture stronger in forward coefficients. Backward coefficients, of course, reflect the capacity of a given sector to drive other economic activities when demand parameters vary (Duarte et al. 2017), covering the direct and the indirect effects of changes. Falling farm output in turn lowers demand for intermediate inputs, reducing VA and driving job losses as an indirect effect worldwide.

By including the water constraint at the Delta in this case (unlike scenario 1, where all reaches are subject to the constraint), the total available water for consumptive uses is conditioned throughout the ERB. Thus, the hypothetical measure involved in this scenario will reduce consumptive water availability in the entire basin, while the model reallocates water to maximize net benefits throughout, triggering a reduction in the land cultivated in areas where apparent water productivity $\left(€ / \mathrm{hm}^{3}\right)$ is lower. Hence, the worst affected regions will be those with higher percentages of land given over to less productive (or valuable) crops. 
Table 2. Impact of percentage increments in the Ebro Delta's EF on VA and employment

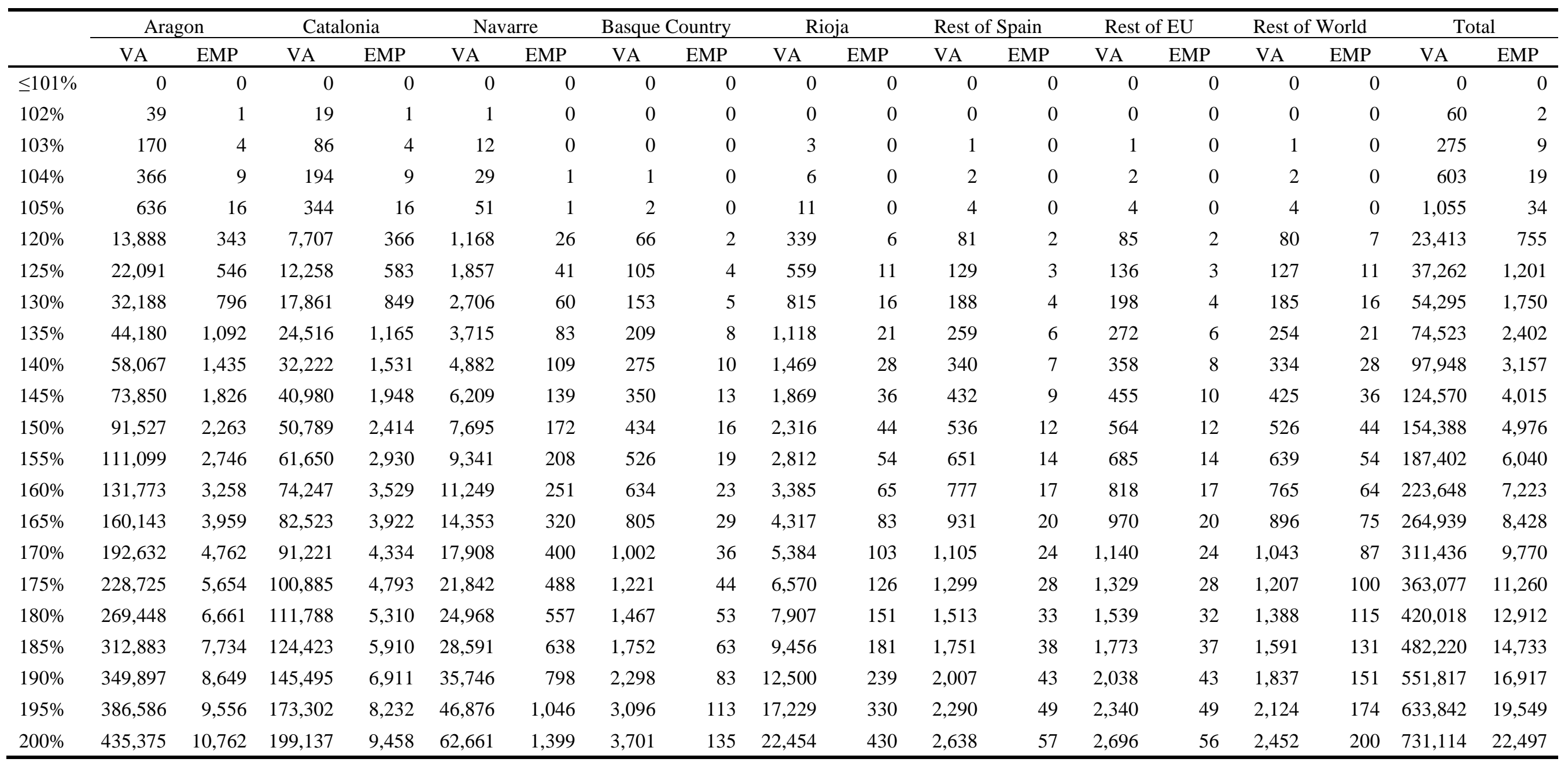

Source: Own work. VA=Value Added (in thousands of euros); EMP = Employment (jobs). The first column of the table shows the percentage of increase in Ebro Delta EF above the legal levels set by the ERB Authority. 


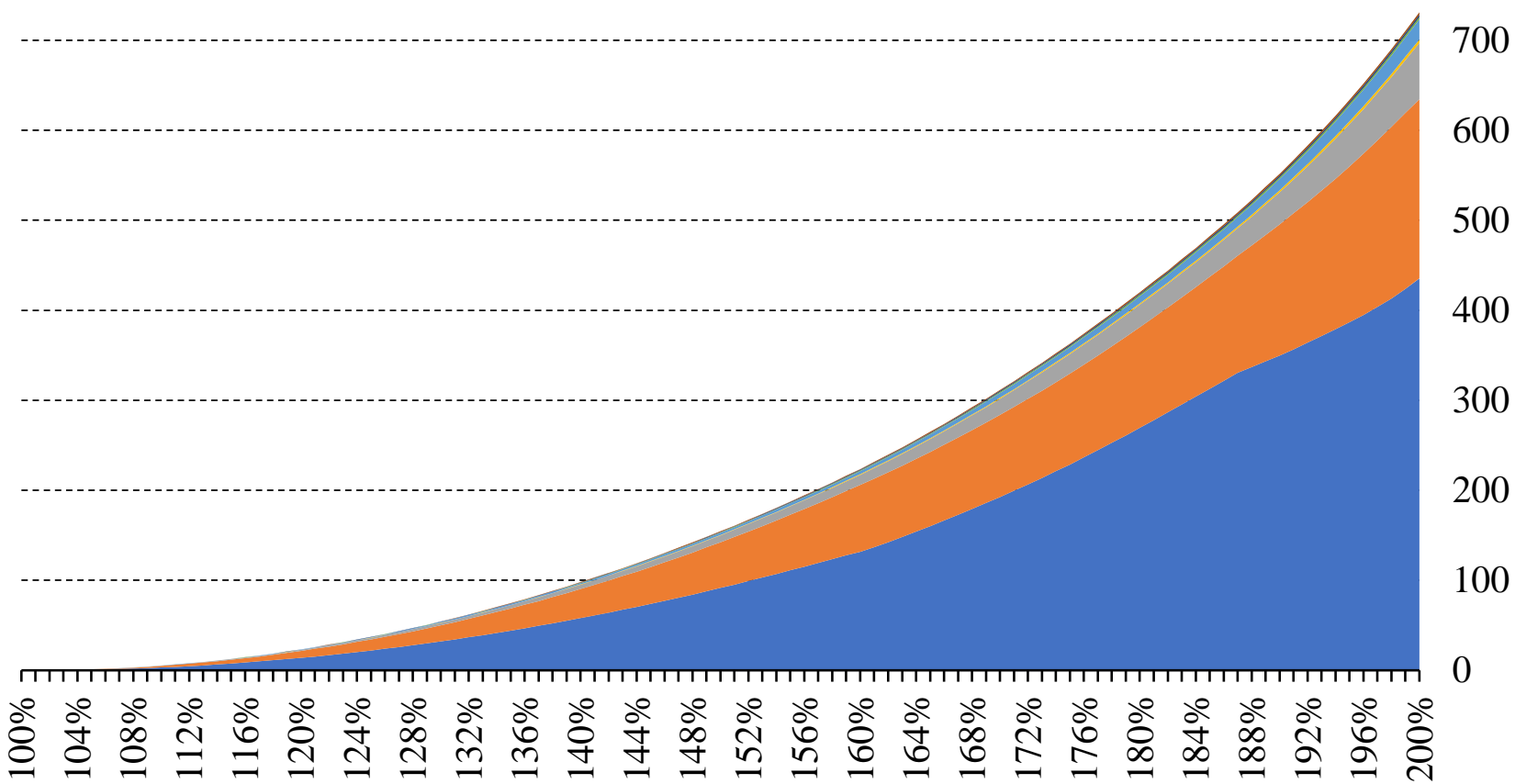

$\square$ ARA $\square$ CAT $\square$ NAV $\square$ B_C $\square$ RIO $\square$ RSP $\square$ REU $\square$ ROW

Fig. 4 Total VA lost (millions of euros) due to percentage increases in Ebro Delta EF. The horizontal axis shows the percentage increase EF in the Ebro Delta and the vertical axis VA losses by autonomous community and macro-regions. $\mathrm{ARA}=$ Aragon, $\mathrm{CAT}=$ Catalonia, NAV=Navarre, B_C=Basque Country, $\mathrm{RIO}=\mathrm{La}$ Rioja, RSP=Rest of Spain, REU=Rest of European Union, ROW=Rest of World.

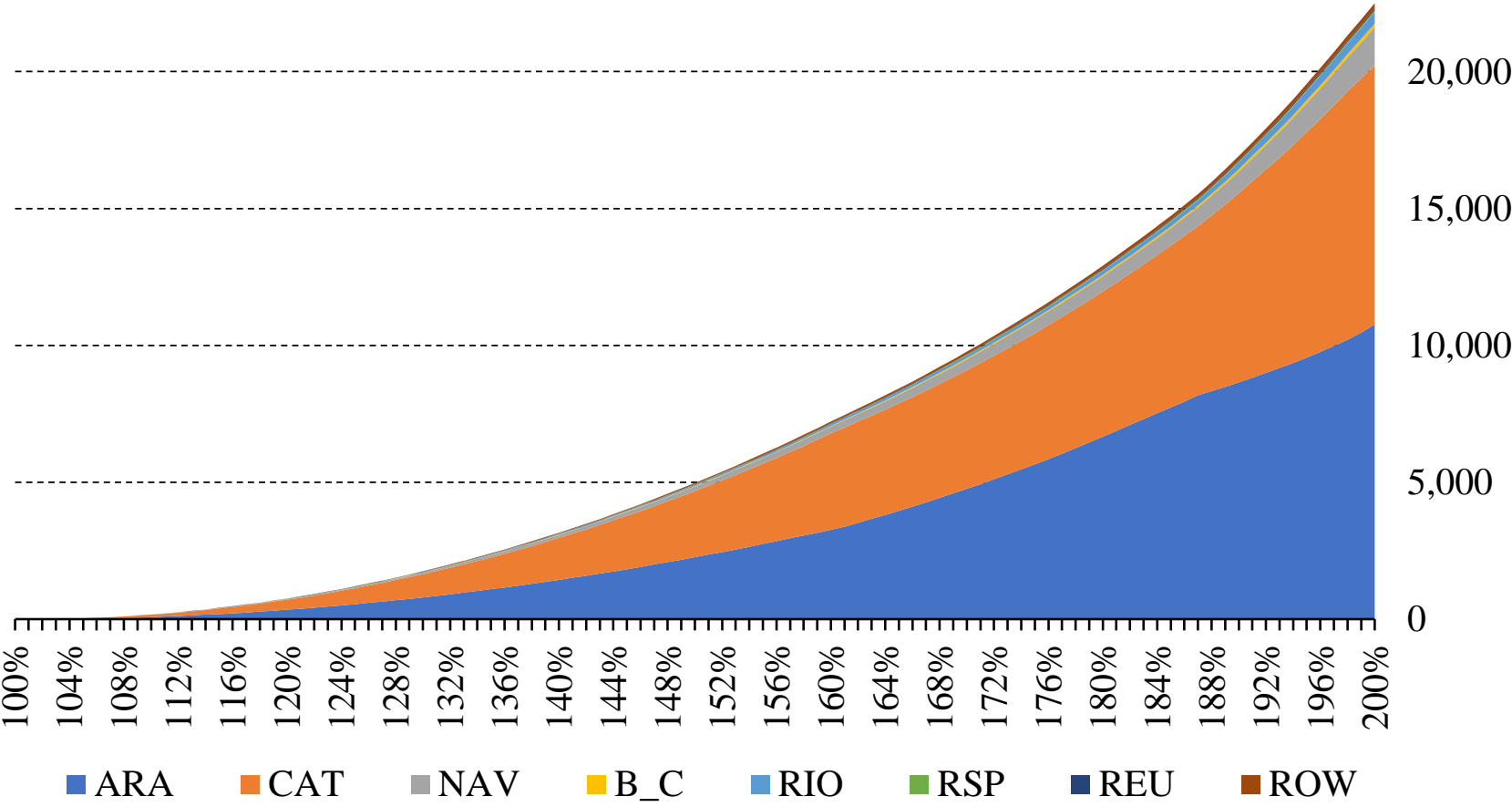

Fig. 5 Total job losses due to percentage increases in Ebro Delta EF. The horizontal axis shows the percentage increase in EF in the Ebro Delta's EF and the vertical axis job losses by autonomous community. 


\section{Discussion and Conclusions}

As mentioned in the Introduction, one of the main objectives of this study was to test whether a standard hydro-economic model can usefully be linked with the information provided by MRIO models. The main advantage of this approach is that it extends the standard description of water flows contained in hydro-economic models to the disaggregated sectoral and regional analysis provided by MRIO models, at the same time allowing the inclusion of consumer demand, investment and other macroeconomic variables in the analysis. The results obtained in both scenarios simulated confirm the viability and usefulness of these models.

The model developed shows the opportunity costs of two different hydrologic scenarios in terms of value added and employment. Both simulations assume increases in EF, but these are applied to all the water flows in the basin in the first and only to the Delta in the second. The model allows simulation of a range of possible hydrological scenarios and water management policies, which could be designed specifically to address specific development goals or to resolve local issues. In the case studied in scenario 2, the hydrological component evaluated is EF in the Ebro Delta, an acutely sensitive a biosphere reserve.

Combining these two frameworks affords the opportunity to progress with comparative analysis between regions, which is important when it is the whole of a river basis that is studied. Indeed, large river basins may even include independent nation states, which requires separate analyses of each country's national interests as well as an overall examination of their common interests. Even when a river basin lies entirely within the borders of a single country, however, a range of different regions, institutions and stakeholders are likely to be involved in policymaking. The methodology described in this paper could be useful in all such cases, offering relevant information for better water governance.

The results obtained would also support assessments of a river basin's capacity to sustain existing or proposed water uses, or of the need to reduce current uses). The opportunity cost (in terms of value added and/or employment) of a change in EF at a specific point will also show whether or not water uses could be increased in the area concerned. When opportunity costs are zero, a river basin could also increase water uses or handle larger environmental flows; where opportunity costs are high, however, the effort required to increase EF might not make sense in a given river reach and it might also be necessary to reduce upstream uses. 
Hence, the combined hydro-economic and MRIO model provides a basis for debate as to policy options and their likely outcomes.

The model presented is the first step in a complex analysis, and it could be refined and improved in a number of ways. To begin with, the hydro-economic part of this study could be extended to include groundwater and non-consumptive water users. Furthermore, the regional structure used could be broken down further using data at the county or municipal level, for example. This would extend the model's capacity for regional capacity to allow a focus on quite specific areas.

All in all, this paper should be treated as an initial proposal to model the link between the economic and the environmental variables in a river basin, showing that integrated inputoutput and hydro-economic models would provide an excellent aid for optimal water planning and, in particular, for the estimation of opportunity costs associated with environmental and water policies.

The assessment of impacts described was based on the assumption of proportional increases in the legally established EF either at all points in the river basis or only at the river mouth. The model clearly reflects the VA and employment impacts of increasing EF in both scenarios, and this opportunity cost should be considered in the definition of water policy proposals. Hence, the proposed methodology provides a baseline for the examination of socio-economic effects, because increases in EF can trigger changes in water availability for consumptive and non-consumptive uses, a factor that inevitably affects farmers behavior through direct and indirect impacts on irrigation. The first scenario discussed evaluates the effects of establishing environmental flows in all river reaches at $50 \%$ of the natural monthly flow. The results obtained show not only how this water constraint affects irrigated farming in each region directly but also how the impact spreads to other sectors and regions. Based on the analysis of the second scenario, meanwhile, it is clear that EF cannot be increased to more than the double the current level without adversely affecting current water uses, resulting in negative impacts on VA and employment. On the plus side, however, it would be quite possible to increase EF to $100 \%$, or to adopt any other water policy that would imply an equivalent water constraint. The results of this scenario also reveal that increases in EF at the mouth of the Ebro would reduce income and employment throughout the river basin, although these effects would not be linear. 
The results obtained from the scenarios described can be seen as a representation of the impact on VA and employment arising from changes in farmers' behavior as they lower their expectations of water availability. However, these effects could in fact be even higher, since any fall in VA will eventually put downward pressure on available household income and consumer spending. The resulting fall in demand might even trigger further falls VA and job losses. This is usually termed an "induced effect" in the input-output literature and it quite naturally represents a next step in the analysis, although this would be a matter for future research.

Finally, combined hydro-economic modeling and the multiregional input-output framework is sufficiently versatile in methodological terms to allow the simulation of a range of hydrological scenarios involving different amounts of available water in each head flow or area analyzed, variations in environmental requirements, changes in water requirements caused, for instance, by rising temperatures, changes in the efficiency of irrigation, the construction of reservoirs, initiatives affecting existing infrastructure (e.g. rebuilding or demolition of dams), changes in industrial water needs, and so on. Finally, this methodology could also usefully be applied to study the resilience of regions in the face of climate change or changes in institutional conditions.

\section{Acknowledgements}

We would like to express our gratitude for the partial funding received from the Spanish Government under the project ECO 2016-74940-P, from the Aragonese Regional Government and FEDER Funds via the S40_17R reference group of the Aragon Government, and grant FPU14/ 01694. The authors would also like to thank the editor of CTEP and the anonymous reviewers for their constructive comments, which have helped to improve the quality of the manuscript.

\section{References}

Acreman MC, Ferguson AJD (2010) Environmental flows and the European Water Framework Directive. Freshw Biol 55:32-48. https://doi.org/10.1111/j.13652427.2009.02181.x

Akter S, Grafton RQ, Merritt WS (2014) Integrated hydro-ecological and economic modeling of environmental flows: Macquarie Marshes, Australia. Agric Water Manag 145:98-109. https://doi.org/10.1016/j.agwat.2013.12.005

Almazán-Gómez MA, Duarte R, Langarita R, Sánchez-Chóliz J (2019) Effects of water reallocation in the Ebro river basin: A multiregional input-output and geographical analysis. $\mathrm{J}$ Environ Manage 241:645-657. https://doi.org/10.1016/j.jenvman.2019.03.042 
Almazán-Gómez MA, Sánchez-Chóliz J (2016) The Mequinenza Reservoir: Its contribution to the Ebro Delta and its potential for economic development - El embalse de Mequinenza: Su aportación al delta del Ebro y su potencialidad para el desarrollo económico (In Spanish). Reg Sect Econ Stud 16:147-166

Almazán-Gómez MA, Sánchez-Chóliz J, Sarasa C (2018) Environmental flow management: An analysis applied to the Ebro River Basin. J Clean Prod 182:838-851. https://doi.org/10.1016/j.jclepro.2018.01.207

Antonelli M, Roson R, Sartori M (2012) Systemic Input-Output Computation of Green and Blue Virtual Water 'Flows' with an Illustration for the Mediterranean Region. Water Resour Manag 26:4133-4146. https://doi.org/10.1007/s11269-012-0135-9

Arthington AH, Bhaduri A, Bunn SE, et al (2018) The Brisbane Declaration and Global Action Agenda on Environmental Flows (2018). Front Environ Sci 6:1-15. https://doi.org/10.3389/fenvs.2018.00045

Ballester A, Mott Lacroix KE (2016) Public Participation in Water Planning in the Ebro River Basin (Spain) and Tucson Basin (U.S., Arizona): Impact on Water Policy and Adaptive Capacity Building. Water 8:273. https://doi.org/10.3390/w8070273

Bonsch M, Popp A, Biewald A, et al (2015) Environmental flow provision: Implications for agricultural water and land-use at the global scale. Glob Environ Chang 30:113-132. https://doi.org/10.1016/j.gloenvcha.2014.10.015

Cai B, Wang C, Zhang B (2017) Worse than imagined: Unidentified virtual water flows in China. J Environ Manage 196:681-691. https://doi.org/10.1016/j.jenvman.2017.03.062

Cazcarro I, Duarte R, Sánchez-Chóliz J (2016) Downscaling the grey water footprints of production and consumption. $\mathrm{J}$ Clean Prod 132:171-183. https://doi.org/10.1016/j.jclepro.2015.07.113

Cazcarro I, Duarte R, Sánchez Chóliz J, Sarasa C (2019) Water and production reallocation in the Spanish agri-food system. Econ Syst Res 5314:1-22. https://doi.org/10.1080/09535314.2019.1693982

Crespo D, Albiac J, Kahil T, et al (2019) Tradeoffs between Water Uses and Environmental Flows: A Hydroeconomic Analysis in the Ebro Basin. Water Resour Manag 33:2301-2317. https://doi.org/10.1007/s11269-019-02254-3

Dietzenbacher E (2005) More on multipliers*. J Reg Sci 45:421-426. https://doi.org/10.1111/j.0022-4146.2005.00377.x

Duarte R, Langarita R, Sánchez-Chóliz J (2017) The electricity industry in Spain: A structural analysis using a disaggregated input-output model. Energy 141:2640-2651. https://doi.org/10.1016/j.energy.2017.08.088

George B, Malano H, Davidson B, et al (2011) An integrated hydro-economic modelling framework to evaluate water allocation strategies I: Model development. Agric Water Manag 98:733-746. https://doi.org/10.1016/j.agwat.2010.12.004

Hai R, Shi H, Zhang B, et al (2015) An ecological information analysis-based approach for assessing the sustainability of water use systems: a case study of the Huaihe River Basin, China. Clean Technol Environ Policy 17:2197-2211. https://doi.org/10.1007/s10098-0150944-7

Harou JJ, Pulido-Velázquez M, Rosenberg DE, et al (2009) Hydro-economic models: Concepts, design, applications, and future prospects. J Hydrol 375:627-643. https://doi.org/10.1016/j.jhydrol.2009.06.037

Hašková S (2017) Holistic Assessment and Ethical Disputation on a New Trend in Solid Biofuels. Sci Eng Ethics 23:509-519. https://doi.org/10.1007/s11948-016-9790-1

Hoa NT, Aviso KB, Kojima N, Tokai A (2018) Structural analysis of the interrelationship between economic activities and water pollution in Vietnam in the period of 2000-2011. Clean Technol Environ Policy 20:621-638. https://doi.org/10.1007/s10098-018-1492-8 
Hoegh-Guldberg O, Jacob D, Taylor M, et al (2018) Impacts of $1.5^{\circ} \mathrm{C}$ Global Warming on Natural and Human Systems. In: Masson-Delmotte V, Zhai P, Pörtner H-O, et al. (eds) Global Warming of $1.5^{\circ} \mathrm{C}$. An IPCC Special Report on the impacts of global warming of $1.5^{\circ} \mathrm{C}$ above pre-industrial levels and related global greenhouse gas emission pathways, in the context of strengthening the global response to the threat of climate change,. pp 175-311

Kahil MT, Dinar A, Albiac J (2015) Modeling water scarcity and droughts for policy adaptation to climate change in arid and semiarid regions. J Hydrol 522:95-109. https://doi.org/10.1016/j.jhydrol.2014.12.042

Kahil MT, Ward FA, Albiac J, et al (2016) Hydro-economic modeling with aquifer-river interactions to guide sustainable basin management. $J$ Hydrol 539:510-524. https://doi.org/10.1016/j.jhydrol.2016.05.057

López-Díaz DC, Lira-Barragán LF, Rubio-Castro E, et al (2018) Optimization of biofuels production via a water-energy-food nexus framework. Clean Technol Environ Policy 20:1443-1466. https://doi.org/10.1007/s10098-017-1395-0

Maneta MP, Torres MDO, Wallender WW, et al (2009) A spatially distributed hydroeconomic model to assess the effects of drought on land use, farm profits, and agricultural employment. Water Resour Res 45:1-19. https://doi.org/10.1029/2008WR007534 Mardoyan A, Braun P (2015) Analysis of Czech Subsidies for Solid Biofuels. Int J Green Energy 12:405-408. https://doi.org/10.1080/15435075.2013.841163

Maroušek J (2014) Novel technique to enhance the disintegration effect of the pressure waves on oilseeds. Ind Crops Prod 53:1-5. https://doi.org/10.1016/j.indcrop.2013.11.048

Maroušek J, Stehel V, Vochozka M, et al (2019) Ferrous sludge from water clarification: Changes in waste management practices advisable. J Clean Prod 218:459-464. https://doi.org/10.1016/j.jclepro.2019.02.037

Milano M, Ruelland D, Dezetter A, et al (2013) Modeling the current and future capacity of water resources to meet water demands in the Ebro basin. J Hydrol 500:114-126. https://doi.org/10.1016/j.jhydrol.2013.07.010

Moriondo M, Bindi M, Kundzewicz ZW, et al (2010) Impact and adaptation opportunities for European agriculture in response to climatic change and variability. Mitig Adapt Strateg Glob Chang 15:657-679. https://doi.org/10.1007/s11027-010-9219-0

Perni Á, Martínez-Paz J, Martínez-Carrasco F (2012) Social preferences and economic valuation for water quality and river restoration: the Segura River, Spain. Water Environ J 26:274-284. https://doi.org/10.1111/j.1747-6593.2011.00286.x

Pulido-Velázquez M, Andreu J, Sahuquillo A, Pulido-Velazquez D (2008) Hydro-economic river basin modelling: The application of a holistic surface-groundwater model to assess opportunity costs of water use in Spain. Ecol Econ 66:51-65. https://doi.org/10.1016/j.ecolecon.2007.12.016

Tan RR, Foo DCY (2018) Integrated multi-scale water management as a climate change adaptation strategy. Clean Technol Environ Policy 20:1123-1125. https://doi.org/10.1007/s10098-018-1551-1

White DJ, Feng K, Sun L, Hubacek K (2015) A hydro-economic MRIO analysis of the Haihe River Basin's water footprint and water stress. Ecol Modell 318:157-167. https://doi.org/10.1016/j.ecolmodel.2015.01.017 